\title{
Reduction in sleep duration and Type A behavior
}

\author{
ROBERT A. HICKS, JOSEPH G. ALLEN, RIMA E. ARMOGIDA, \\ MARCIA A. GILLILAND, and ROBERT J. PELLEGRINI \\ San Jose State University, San Jose, California 95192
}

\begin{abstract}
As a test of the hypothesis that sleep habits are associated with the level of Type A behavior, the responses of 180 college students to the Jenkins Activity Survey and a selfreport sleep questionnaire were used to demonstrate a direct relationship between amount of sleep reduction and level of Type A behavior. In addition to providing support for the hypothesis, these data serve to suggest that both sleep reduction and sleep duration be taken into account in defining shortened sleep.
\end{abstract}

In a recent paper, Hicks and his colleagües (Hicks, Pellegrini, Martin, Garbesi, Elliott, \& Hawkins, 1979) reported a significant inverse relationship between normal habitual sleep duration and score on Glass' (1977) modification, for college students, of the Jenkins Activity Survey (JAS), which is the test commonly used to identify Type A behavior. The purpose of this report is to provide data that elaborate further the relationship(s) between sleep patterns and Type A behavior.

In discussing the aforementioned sleep duration/ Type A relationship, Hicks, Pellegrini, Martin, Garbesi, Elliott, and Hawkins (1979) advanced the hypothesis that an individual's normal habitual sleep duration might be implicated in the development of Type A behavior patterns. In part, this hypothesis was predicted on the basis of research (e.g., Hartmann, 1973) that has served to demonstrate that as sleep duration is shortened, there is a proportional loss of REM sleep, but little or no loss of NREM Stages 3 and 4. Thus, Hicks, Pellegrini, Martin, Garbesi, Elliott, and Hawkins speculated that individuals who adopt a strategy of coping with a demanding situation (e.g., college) by gaining work time by shortening their habitual sleep duration are more likely to experience what could be construed (in this case) as both the positive and the negative behavioral consequences of reduced REM sleep. That is, on the positive side, deprivation of REM sleep has been associated with increased levels of motivation (e.g., Vogel, 1979), energy (e.g., Hicks \& Paulus, 1973), and aggressiveness (e.g., Hicks, Moore, Hayes, Phillips, \& Hawkins, 1979). While on the negative side, reductions of REM sleep have been associated with increased susceptibility to stressors (Hicks \& Sawrey, 1978) and restrictions in the diversity of coping potential (Glaubman, Orbach, Aviram, Frieder, Frieman, Pelled, \& Glaubman, 1978; Greenberg, 1977; Hawkins, Phillips,

We thank Signe Gary for her help in preparing this manuscript. Address all correspondence to Robert A. Hicks, Department of Psychology, San Jose State University, San Jose, California 95192.
Moore, Dunbar, \& Hicks, in press). Here, it should be noted that the positive-negative behavioral dichotomy that we have drawn fits Glass' (1977) hypothesis that the Type A person is both aggressively energetic and less able to cope with stress, and hence the well-documented increased frequency of coronary heart disease shown by Type A individuals.

By exclusion, an impression conveyed by the Hicks, Pellegrini, Martin, Garbesi, Elliott, and Hawkins (1979) study was that the critical parameter associated with level of Type A behavior is the individual's habitual sleep duration. In this regard, Webb (1979) has recently drawn a potentially useful distinction between short sleep and shortened sleep. He defined the former as a long-established pattern of short sleep that could, perhaps, best be thought of as a natural pattern of sleep. The latter was defined as a more recently adopted pattern of sleep, which constituted a shortening of a preexisting sleep habit. This distinction is important to the aforementioned sleep duration/Type A relationship, for as Webb (Note 1) suggested to us, it may be the case that only shortened sleepers show an attenuation of REM sleep. Thus, it seemed plausible to us that there should be a positive correlation between JAS scores and the number of hours by which sleep had been shortened from a previously existing sleep duration.

\section{METHOD}

To measure the relationship between sleep reduction and level of Type A behavior, we first tested more than 300 university students with Glass' (1977) version of the JAS and a sleep questionnaire. On the sleep questionnaire, the students responded to these questions: "How long do you sleep each night?" "How long have you been sleeping this long?" A set of questions designed to determine whether the respondents were satisfied with their sleep durations were asked, and finally, these students were asked to recall how long they had slept prior to changing their sleep durations (if, of course, they had reported such a change). In selecting the 180 students who were the subjects of this study, we eliminated from consideration individuals who failed to provide all the requisite information, reported lengthening their sleep, expressed dissatisfaction with 
Table 1

Means and Standard Deviations for the JAS and Current Hours of Sleep Duration for Each Sleep-Reduction Group

\begin{tabular}{|c|c|c|c|c|c|c|}
\hline \multirow{2}{*}{$\begin{array}{l}\text { Hours of } \\
\text { Sleep Re- } \\
\text { duction }\end{array}$} & \multicolumn{2}{|c|}{$\mathbf{N}$} & \multicolumn{2}{|c|}{ JAS Score } & \multicolumn{2}{|c|}{ Sleep Duration } \\
\hline & Total & Type A & Mean & SD & Mean & SD \\
\hline 0 & 30 & 7 & 7.0 & 2.5 & 7.7 & .7 \\
\hline 1 & 50 & 20 & 7.9 & 3.4 & 7.1 & .8 \\
\hline 2 & 66 & 35 & 8.4 & 3.0 & 6.9 & 1.0 \\
\hline $3(+)$ & 34 & 31 & 10.9 & 2.1 & 5.9 & 1.1 \\
\hline
\end{tabular}

their sleep, or had changed their sleep durations within the last 6 month period.

For these 180 students, we scored the JAS using Glass' (1977) scoring procedures. In addition, a sleep reduction score (to the nearest $1 \mathrm{~h}$ ) was determined for each subject by computing the difference between an individual's former and current sleep durations. For the purposes of the data analyses, each subject was, on the basis of his sleep reduction score, assigned to one of the four sleep reduction groups listed in Table 1 .

\section{RESULTS AND DISCUSSION}

First, for each sleep reduction group, the means and the standard deviations for the JAS and the current duration of sleep were computed. These values, together with the number of students in each sleep reduction group, are given in Table 1.

Next, we determined the number of persons in each group that could be classed as Type A. This was done using a procedure that is compatible with the one suggested by Glass (1977). That is, we counted the number of individuals in each sleep reduction group who scored above the San Jose State University JAS mean (computed from a separate sample of 1,010 students: mean $=8.10$ ). That is, using this procedure, all subjects were classified as either Type A (JAS $\geqslant 9)$ or as Type B (JAS < 9). In the interest of brevity, only the number of Type $A$ individuals in each sleep reduction group is reported in Table 1.

The differences between the JAS means and the current sleep duration means, listed in Table 1, were tested using separate one-way analyses of variance. The results of these analyses for both the JAS and sleep duration variables were significant $[\mathrm{F}(3,179)=9.03$, $\mathrm{p}<.001$, and $\mathrm{F}(3,179)=21.08, \mathrm{p}<.001$, respectively]

As can be seen by inspecting the patterns of JAS responses, congruent with our prediction, there was a positive correlation between amount of sleep reduction and score on the JAS. To estimate the magnitude of this correlation, we computed and estimated $\omega^{2}$ from the ANOVA. This value was .12, which corresponds roughly to a correlation of .34 between hours of sleep reduction and level of Type $\mathrm{A}$ behavior. We also esti- mated the correlation between these variables by testing the differences between the Type A/Type B distributions for the sleep reduction groups, with these results: $\chi^{2}=33.67(\mathrm{p}<.001)$ and $\phi^{\prime}=.43$.

When considered together, these data support the hypothesis that increased levels of Type A behavior are associated with habitual shortened sleep. In a general way, these data help to reinforce the view that sleep patterns may be important to certain motivational and affective aspects of human functioning. However, a fair amount of research is needed before the parameters of these relationships can be adequately described. In this regard, this study calls attention to the value of using sleep reduction as a measure of shortened sleep. However, when we view our results together with those of Hicks, Pellegrini, Martin, Garbesi, Elliott, and Hawkins (1979), we see tenuous evidence that, for now, suggests that both sleep reduction and sleep duration should be taken into account in defining shortened sleep.

\section{REFERENCE NOTE}

1. Webb, W. B. Personal communication, September 1979.

\section{REFERENCES}

Glass, D. C. Behavior patterns, stress, and coronary disease. Hillsdale, N.J: Erlbaum, 1977.

Glaubman, H., Orbach, I., Aviram, O., Frieder, I., Frieman, M., Pelled, O., \& Glaubman, R. REM deprivation and divergent thinking. Psychophysiology, 1978, 15, 75-79.

GreEnBERG, R. On understanding sleep disorders and their psychopathology. McLean Hospital Journal, 1977, 2, 139-146.

HARTMANN, E. Sleep requirement: Long sleepers, short sleepers, variable sleepers, and insomniacs. Psychosomatics, 1973, 14, 95-103.

Hawkins, J., Phillips, N., Moore, J. D., Dunbar, S., \& Hicks, R. A. Emotionality and REMD: A rat swimming model. Physiology \& Behavior, in press.

Hicks, R. A., Moore, J. D., Hayes, C., Phillips, N., \& HAwKINS, J. REM sleep deprivation increases aggressiveness in male rats. Physiology \& Behavior, 1979, 22, 1097-1100.

Hicks, R. A., \& Paulus, M. Effects of rapid eye movement sleep deprivation on the performance of rats in a T-maze. Psychological Record, 1973, 23, 89-92.

Hicks, R. A., Pellegrini, R. J., Martin, S., Garbesi, L. Elliot,, D., \& Hawkins, J. Type A behavior and normal habitual sleep duration. Bulletin of the Psychonomic Society, 1979, 14, 185-186.

Hicks, R. A., \& SAwrey, J. M. REM sleep deprivation and stress susceptibility in rats. Psychological Record, 1978, 28, 187-191.

VoGel, G. W. A motivational function of REM sleep. In R. Drucker-Colin, M. Shkurovich, \& M. B. Sterman (Eds.), The functions of sleep. New York: Academic Press, 1979.

We в, W. B. Are short and long sleepers different? Psychological Reports, 1979, 44, 259-264.

(Received for publication June 21, 1980.) 